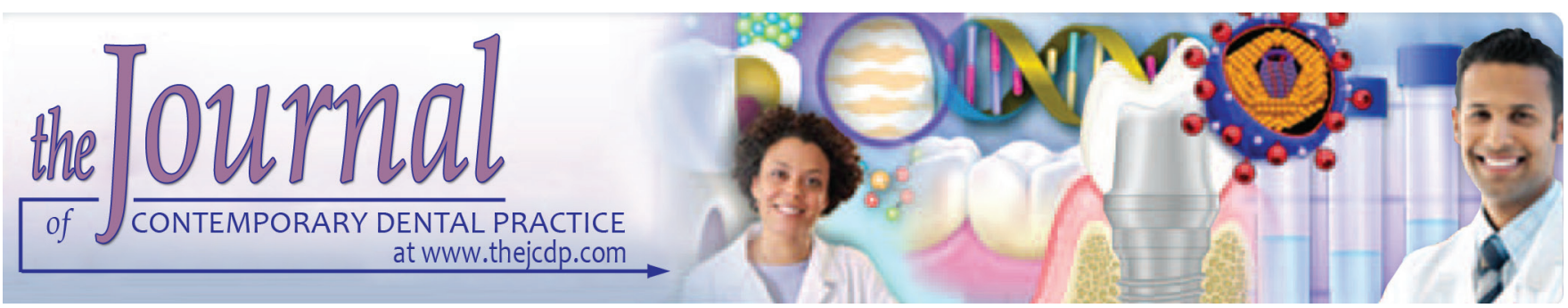

\title{
Antibacterial Efficacy of Neem (Azadirachta indica) Extract against Enterococcus faecalis: An in vitro Study
}

Mohammed Mustafa

\begin{abstract}
Introduction: Debridement and disinfection of the root canal is a crucial step in the success of endodontic treatment. Several antimicrobial agents alone or in combination are used to achieve this. The objective of this in vitro study was to assess the antimicrobial efficacy of neem (Azadirachta indica) extract against Enterococcus faecalis.
\end{abstract}

Materials and methods: Neem leaf extract, $2 \%$ chlorhexidine, $3 \%$ sodium hypochlorite were used to assess the antimicrobial efficiency. Agar well diffusion test was used to study the antimicrobial efficacy with saline as control. The zone of inhibition was recorded, tabulated, and analyzed statistically with the help of IBM Statistical Package for the Social Sciences statistics version 20 using analysis of variance test.

Results: All the three medicaments showed well-defined and comparable zones of inhibition around their respective wells. All values were significantly higher than the control group. Analysis of variance showed significant difference between zone diameters of chlorhexidine, neem leaf extract, and $3 \%$ sodium hypochlorite against $E$. faecalis $(p<0.05)$.

Conclusion: From the present study, it can be concluded that neem leaf extract shows comparable zones of inhibition with that of chlorhexidine and sodium hypochlorite.

Clinical significance: Neem leaf extract has significant antimicrobial activity against $E$. faecalis and thus opens the perspectives for the use of neem extract as an intracanal medication.

Keywords: Antimicrobial activity, Chlorhexidine, Enterococcus faecalis, Intracanal medications, Neem extract, Sodium hypochlorite.

How to cite this article: Mustafa M. Antibacterial Efficacy of Neem (Azadirachta indica) Extract against Enterococcus faecalis: An in vitro Study. J Contemp Dent Pract 2016;17(10):791-794.

Division of Endodontic, Department of Conservative Dental Sciences, College of Dentistry, Prince Sattam Bin Abdulaziz University, Al-Kharj, Kingdom of Saudi Arabia

Corresponding Author: Mohammed Mustafa, Assistant Professor and Head of Endodontic Division, Department of Conservative Dental Sciences, College of Dentistry, Prince Sattam Bin AbdulAziz University, P.O.BOX: 153, AlKharj - 11942 Kingdom of Saudi Arabia, Phone: 00966-11-5886240, email: ma.mustafa@psau.edu.sa
Source of support: Nil

\section{Conflict of interest: None}

\section{INTRODUCTION}

Eradication of bacteria from the root canal system is important in ensuring the long-term success of root canal therapy. The microorganisms are the primary etiological agent in endodontic infections, and failure to eradicate them affects the outcome of endodontic therapy. ${ }^{1}$ Studies have shown that the bacterial flora in endodontic infections is polymicrobial, with a predominance of anaerobic species. ${ }^{2,3}$ This is mainly achieved through the reduction of bacteria by debridement of the root canal system utilizing mechanical preparation of the canals combined with chemical interventions. Several areas of the root canal walls, specifically in the apical third, are difficult to clean mechanically. ${ }^{4-7}$

Enterococcus faecalis is part of the human normal flora and an important pathogen in opportunistic infections in humans. E. faecalis is rarely present in primary apical periodontitis, but it is the dominant microorganism in root canal-treated teeth presenting with posttreatment apical periodontitis. ${ }^{8}$ Eradication of E. faecalis from the root canal remains a challenge, since it is resistant to a variety of antimicrobial agents. Studies have also shown that E. faecalis may be one of the reasons of failure of endodontic treatments. ${ }^{9}$ The control and suppression of E. faecalis in these dental procedures are of primarily importance in decreasing the penetration of bacteria inside the dentinal tubules and also limiting the formation of any relationship with other microorganisms, as in virulence factors, environment, and the biofilms. ${ }^{10-12}$

Elimination of bacteria can be achieved with mechanical preparation combined with the use of antimicrobial irrigants. ${ }^{13}$ The most commonly used irrigant is sodium hypochlorite $(\mathrm{NaOCl})$, introduced by Dakin. ${ }^{14}$ Some of the drawbacks of $\mathrm{NaOCl}$ are toxicity, unpleasant odor 
and taste, inability to completely remove the microorganisms, and smear from the root canal. ${ }^{15-17}$ Due to the side effects of these agents and the development of resistant strains, research is still ongoing to find ideal root canal disinfection. Herbal extracts have also been tried as root canal irrigants. ${ }^{18-21}$

Neem (Azadirachta indica) has a wide range of various therapeutic properties based on its characteristics, such as antifungal, antibacterial, antioxidant, antiviral, antiinflammatory, analgesic, antipyretic, and immune stimulant activity. ${ }^{22}$ Azadirachta indica (neem) leaf extract is a commonly used antibacterial agent and little information is available on its usage as a potential agent in root canal irrigation. ${ }^{23,24}$ Hence, the present study was conducted to evaluate the antimicrobial activity of neem leaf extract and to compare it with $2 \%$ chlorhexidine gluconate and $3 \% \mathrm{NaOCl}$.

\section{MATERIALS AND METHODS}

The study was approved by the departmental review board. A single species of E. faecalis American Type Culture Collection no 29212 was used to test the sensitivity. The bacterial culture was prepared in sterile brain heart infusion (BHI) broth (Oxoid, England) and adjusted spectrophotometrically to an optical density of $625 \mathrm{~nm}$ corresponding to match the turbidity of a McFarland 0.5 scale. The sensitivity assay was done using Neem leaf (A. indica) extract $2 \%$ chlorhexidine and $3 \% \mathrm{NaOCl}$.

\section{Preparation of Neem Leaf Extract}

Fresh neem leaves were used for the study. Neem leaves were thoroughly cleaned in distilled water and then weighed and recorded. About $25 \mathrm{gm}$ of fresh neem leaves was mixed with $50 \mathrm{~mL}$ of absolute alcohol and the mixture was macerated for 1 to 2 minutes and the separation of the course residue was done using muslin cloth filtration. Same separation procedure was repeated for the coarse residue using alcohol. Both these extracted parts were later pooled together and then again filtered using fast filter paper. Total volume of $25 \mathrm{~mL}$ was taken after separation of the alcohol from the extract and then the remaining extract was stored in amber-colored airtight bottle. ${ }^{25,26}$

\section{Agar-diffusion Test}

The cultures of E. faecalis were made on BHI agar. The agar was incubated at $37^{\circ} \mathrm{C}$ for overnight duration on a rotary shaker, and the growth of the bacteria was checked for changes in turbidity after a period of 24 hours. Agar well diffusion method was used for assessing the antimicrobial efficacy of the three irrigating materials used in the study.
Preparation of the BHI agar plates was followed by spread of the cultures on these prepared plates. After this, $6 \mathrm{~mm}$ diameter circles were made in these agar plates; $3 \% \mathrm{NaOCl}$, chlorhexidine, neem leaf extract, and normal saline were added to the respective wells. These agar plates were kept in an incubator for 24 hours at a temperature of $37^{\circ} \mathrm{C}$. Normal saline was used as a control. Agar plates were removed after the period of incubation, and the zones of inhibition were recorded. Similar experiment was also done simultaneously on five BHI agar culture plates.

Recording of the zones of inhibition was done for all the culture plates and the results were analyzed statistically with the help of IBM Statistical Package for the Social Sciences statistics version 20 using analysis of variance test.

\section{RESULTS}

All the three medicaments showed well-defined zones of inhibition around their respective wells except the control well (Fig. 1). Analysis of variance showed significant difference between zone diameters of $3 \% \mathrm{NaOCl}$, chlorhexidine, and neem leaf extract against $E$. faecalis $(\mathrm{p}<0.05)$. Maximum antimicrobial activity was shown by $2 \%$ chlorhexidine (20.45), followed by $3 \% \mathrm{NaOCl}(19.22)$ and neem leaf extract (17.19). Neem leaf extract showed comparable zones of inhibition to $2 \%$ chlorhexidine and $3 \% \mathrm{NaOCl}$ (Table 1 and Graph 1).

\section{DISCUSSION}

Chemomechanical preparation is of paramount importance in successful endodontic treatment. Completely eliminating intracanal bacterial populations or reducing them to levels that are compatible with periradicular tissue healing are the main microbiologic goals of the chemomechanical preparation of infected root canals. ${ }^{27}$ Bacteria persisting after chemomechanical procedures

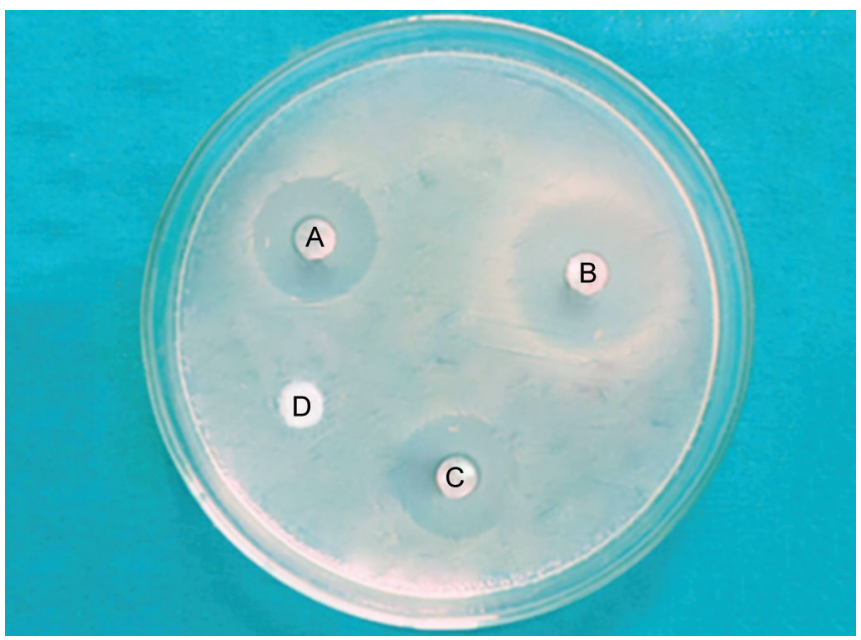

Fig. 1: Zones of inhibition: (A) $2 \%$ chlorhexidine; (B) $3 \%$ $\mathrm{NaOCl}$; (C) neem leaf extract; and (D) saline 
Table 1: Comparison of the zones of inhibition of the root canal irrigants against $E$. faecalis

\begin{tabular}{lll}
\hline Group & $\begin{array}{l}\text { Zone of inhibition } \\
(\text { Mean } \pm \text { SD) }\end{array}$ & Significance \\
\hline Neem leaf extract & $17.70 \pm 2.54$ & $\mathrm{p}<0.05^{*}$ \\
$2 \%$ Chlorhexidine & $20.30 \pm 1.57$ & \\
$3 \% \mathrm{NaOCl}$ & $19.50 \pm 1.90$ & \\
Saline & $0.00 \pm 0.00$ & \\
\hline
\end{tabular}

SD: Standard deviation, *Significant

at levels detectable by culturing techniques might negatively influence the treatment outcome. ${ }^{28}$ The most frequently isolated microorganisms before root canal treatment include Gram-negative anaerobic rods, Grampositive anaerobic cocci, Gram-positive anaerobic and facultative rods, Lactobacillus species, and Gram-positive facultative Streptococcus species. ${ }^{29}$ During root canal treatment, the obligate anaerobes are easily eradicated. Facultative anaerobes are more likely to survive chemomechanical instrumentation and root canal medication. ${ }^{30}$

The irrigants that are currently used as disinfectant in root canal therapy are $\mathrm{NaOCl}$, chlorhexidine, ethylenediaminetetraacetic acid, and a mixture of tetracycline. ${ }^{31}$ Even though $\mathrm{NaOCl}$ is widely used, extrusion to the tissue may cause severe pain, burning sensation, inflammation, and possible delayed healing. ${ }^{32}$

The increased resistance of microbial strains to antimicrobial agents and adverse side effects have raised the essentiality for the search of new herbal alternatives. Recently, herbal compounds attracted greater attention because of their useful beneficial effects. ${ }^{33}$ The observations from the present study showed that neem leaf extract has comparable antimicrobial effects to $\mathrm{NaOCl}$ and chlorhexidine. Neem (A. indica) is predominantly found in the Indian subcontinent. The bark, leaves, and seeds are used to make medicine and less frequently, the root, flower, and fruit are also used. Neem leaf is used for leprosy, eye disorders, bloody nose, intestinal worms, stomach upset, loss of appetite, skin ulcers, diseases of the heart and blood vessels, fever, diabetes, gingivitis, and liver problems. ${ }^{34}$

In this study, the antimicrobial efficacy of neem has been compared with that of the chlorhexidine gluconate and $\mathrm{NaOCl}$, and it was found that neem efficacy was comparable to that of other commonly used gold standard compounds. This observation is in agreement with earlier study by Dubey et $\mathrm{al}^{35}$ who found the antimicrobial efficacy of neem leaf extract to that of the Biopure MTAD and 2.5\% NaOCl. Further studies are required to establish the antimicrobial effects of neem extract against wider spectrum of microorganisms responsible for the periapical pathology.

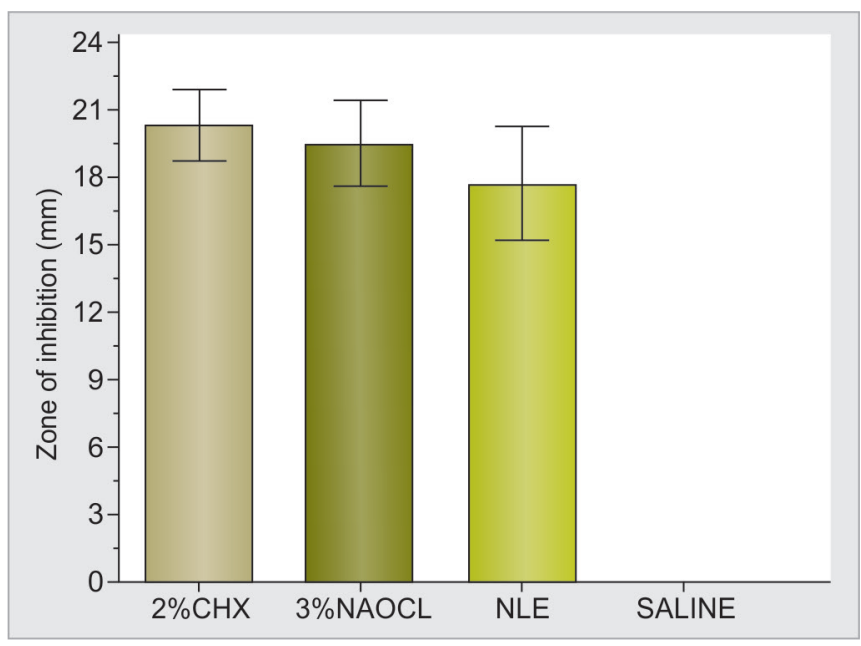

Graph 1: The zones of inhibition of the three root canal irrigants against $E$. faecalis ( $\mathrm{CHX}$ : Chlorhexidine, $\mathrm{NaOCl}$ : Sodium hypochlorite, NLE: Neem leaf extract)

\section{CONCLUSION}

In this study, it was shown that the zone of inhibition in the agar diffusion test showing the antimicrobial efficiency of the neem extract was comparable to that of $2 \%$ chlorhexidine and $3 \% \mathrm{NaOCl}$. Therefore, it can be concluded that neem leaf extract could be used as an alternative agent in root canal disinfection. However, further in vitro studies on its toxicological effects and optimal concentration against a wider spectrum of microorganisms have to be established.

\section{REFERENCES}

1. Henriques LC, de Brito LC, Tavares WL, Teles RP, Vieira LQ, Teles FR, Sobrinho AP. Microbial ecosystem analysis in root canal infections refractory to endodontic treatment. J Endod 2016 Aug;42(8):1239-1245.

2. Kim SY, Shin Y, Lee CY, Jung IY. In vivo quantitative evaluation of live and dead bacteria in root canal infection by using propidium monoazide with real-time PCR. J Endod 2013 Nov;39(11):1359-1363.

3. Aw V. Discuss the role of microorganisms in the aetiology and pathogenesis of periapical disease. Aust Endod J 2016 Aug;42(2):53-59.

4. al-Khatib ZZ, Baum RH, Morse DR, Yesilsoy C, Bhambhani S, Furst ML. The antimicrobial effect of various endodontic sealers. Oral Surg Oral Med Oral Pathol 1990 Dec;70(6):784-790.

5. Brito PR, Souza LC, Machado de Oliveira JC, Alves FR, DeDeus G, Lopes HP, Siqueira JF Jr. Comparison of the effectiveness of three irrigation techniques in reducing intracanal Enterococcus faecalis populations: an in vitro study. J Endod 2009 Oct;35(10):1422-1427.

6. Desai P, Himel V. Comparative safety of various intracanal irrigation systems. J Endod 2009 Apr;35(4):545-549.

7. Howard RK, Kirkpatrick TC, Rutledge RE, Yaccino JM. Comparison of debris removal with three different irrigation techniques. J Endod 2011 Sep;37(9):1301-1305.

8. Stuart CH, Schwartz SA, Beeson TJ, Owatz CB. Enterococcus faecalis: its role in root canal treatment failure and current concepts in retreatment. J Endod 2006 Feb;32(2):93-98. 
9. Castilho AL, Saraceni CH, Díaz IE, Paciencia ML, Suffredini IB. New trends in dentistry: plant extracts against Enterococcus faecalis. The efficacy compared to chlorhexidine. Braz Oral Res 2013 Mar-Apr;27(2):109-115.

10. Anderson AC, Hellwig E, Vespermann R, Wittmer A, Schmid M, Karygianni L, Al-Ahmad A. Comprehensive analysis of secondary dental root canal infections: a combination of culture and culture-independent approaches reveals new insights. PLoS One 2012 Nov;7(11):e49576.

11. Wang QQ, Zhang $\mathrm{CF}, \mathrm{Chu} \mathrm{CH}$, Zhu XF. Prevalence of Enterococcus faecalis in saliva and filled root canals of teeth associated with apical periodontitis. Int J Oral Sci 2012 Mar;4(1):19-23.

12. Zoletti GO, Pereira EM, Schuenck RP, Teixeira LM, Siqueira JF Jr, dos Santos KR. Characterization of virulence factors and clonal diversity of Enterococcus faecalis isolates from treated dental root canals. Res Microbiol 2011 Feb-Mar;162(2):151-158.

13. Ferrer-Luque CM, Bejarano I, Ruiz-Linares M, Baca P. Reduction in Enteroccocus faecalis counts - a comparison between rotary and reciprocating systems. Int Endod J 2014 Apr;47(4):380-386.

14. Dakin HD. On the use of certain antiseptic substances in the treatment of infected wounds. Br Med J 1915 Aug;2(2852):318-320.

15. Chang YC, Huang FM, Tai KW, Chou MY. The effect of sodium hypochlorite and chlorhexidine on cultured human periodontal ligament cells. Oral Surg Oral Med Oral Pathol Oral Radiol Endod 2001 Oct;92(4):446-450.

16. Busslinger A, Sener B, Barbakow F. Effects of sodium hypochlorite on nickel-titanium Lightspeed instruments. Int Endod J 1998 Jul;31(4):290-294.

17. Shuping GB, Orstavik D, Sigurdsson A, Trope M. Reduction of intracanal bacteria using nickel-titanium rotary instrumentation and various medications. J Endod 2000 Dec;26(12):751-755.

18. Mistry KS, Sanghvi Z, Parmar G, Shah S. The antimicrobial activity of Azadirachta indica, Mimusops elengi, Tinospora cardifolia, Ocimum sanctum and 2\% chlorhexidine gluconate on common endodontic pathogens: an in vitro study. Eur J Dent 2014 Apr;8(2):172-177.

19. Mistry KS, Sanghvi Z, Parmar G, Shah S, Pushpalatha K. Antibacterial efficacy of Azadirachta indica, Mimusops elengi and $\%$ CHX on multispecies dentinal biofilm. J Conserv Dent 2015 Nov-Dec;18(6):461-466.

20. Saxena D, Saha SG, Saha MK, Dubey S, Khatri M. An in vitro evaluation of antimicrobial activity of five herbal extracts and comparison of their activity with $2.5 \%$ sodium hypochlorite against Enterococcus faecalis. Indian J Dent Res 2015 Sep-Oct;26(5):524-527.

21. Tyagi SP, Sinha DJ, Garg P, Singh UP, Mishra CC, Nagpal R. Comparison of antimicrobial efficacy of propolis, Morinda citrifolia, Azadirachta indica (Neem) and 5\% sodium hypochlorite on Candida albicans biofilm formed on tooth substrate: an in vitro study. J Conserv Dent 2013 Nov;16(6):532-535.

22. Subapriya R, Nagini S. Medicinal properties of neem leaves: a review. Curr Med Chem Anticancer Agents 2005 Mar;5(2):149-156.

23. Dutta A, Kundabala M. Antimicrobial efficacy of endodontic irrigants from Azadirachta indica: an in vitro study. Acta Odontol Scand 2013 Nov;71(6):1594-1598.

24. Dutta A, Kundabala M. Comparative anti-microbial efficacy of Azadirachta indica irrigant with standard endodontic irrigants: a preliminary study. J Conserv Dent 2014 Mar;17(2):133-137.

25. Owolabi LL, Gbotolorun SC, Akpantah AO, Ekong MO, Eluwa MA, Ekanem TB. Effect of methanolic extract of Neem leaf (Azadirachta indica) on ovarian histology and hormonal milleu. Nig Q J Hosp Med 2008 Oct-Dec;18(4):194-197.

26. Nayak A, Nayak RN, Soumya B, Bhat K, Kudalkar M. Evaluation of antibacterial and anticandidial efficacy of aqueous and alcoholic extract of neem (Azadirachta indica): an in vitro study. Int J Res Ayurveda Pharm 2011;2:230-235.

27. Rôças IN, Siqueira JF Jr. Root canal microbiota of teeth with chronic apical periodontitis. J Clin Microbiol 2008 Nov;46(11):3599-3606

28. Sjögren U, Figdor D, Persson S, Sundqvist G. Influence of infection at the time of root filling on the outcome of endodontic treatment of teeth with apical periodontitis. Int Endod J 1997 Sep;30(5):297-306.

29. Sundqvist G. Taxonomy, ecology, and pathogenicity of the root canal flora. Oral Surg Oral Med Oral Pathol 1994 Oct;78(4):522-530.

30. Chávez De Paz LE, Dahlén G, Molander A, Möller A, Bergenholtz G. Bacteria recovered from teeth with apical periodontitis after antimicrobial endodontic treatment. Int Endod J 2003 Jul;36(7):500-508.

31. Zehnder M. Root canal irrigants. J Endod 2006 May;32(5): 389-398.

32. Gomes BP, Ferraz CC, Vianna ME, Berber VB, Teixeira FB, Souza-Filho FJ. In vitro antimicrobial activity of several concentrations of sodium hypochlorite and chlorhexidine gluconate in the elimination of Enterococcus faecalis. Int Endod J 2001 Sep;34(6):424-428.

33. Venkateshbabu N, Anand S, Abarajithan M, Sheriff SO, Jacob PS, Sonia N. Natural therapeutic options in endodonticsa review. Open Dent J 2016 May;10:214-226.

34. Biswas K, Chattopadhyay I, Banerjee RK, Bandyopadhyay U. Biological activities and medicinal properties of neem (Azadirachta indica). Curr Sci 2002 Jun;82(11):1336-1345.

35. Dubey S, Chaodary M, Gupta P. Comparative study of the antimicrobial efficiency of neem leaf extract, sodium hypochlorite and biopure MTAD - an in vitro study. Indian J Dent Adv 2012;4(1):740-743. 